\title{
Nasal Response from Formaldehyde Exposure Used as Cadaver Preservative among Pre-Clinical Medical Students in a Nigerian Medical College
}

\author{
Mohammed Abdullahi 1* , Abdullahi Daudu Zagga'2, Kufre Robert Iseh¹, \\ Stanley Baba Amutta ${ }^{1}$, Daniel Aliyu ${ }^{1}$ \\ ${ }^{1}$ Department of Ear, Nose and Throat, Usman Danfodiyo University Teaching Hospital, Sokoto, Nigeria \\ ${ }^{2}$ Department of Anatomy, College of Health Science, Usman Danfodiyo University, Sokoto, Nigeria \\ Email: "mabdullahi7174@gmail.com
}

Received 20 May 2014; revised 18 June 2014; accepted 2 July 2014

Copyright (C) 2014 by authors and Scientific Research Publishing Inc.

This work is licensed under the Creative Commons Attribution International License (CC BY).

http://creativecommons.org/licenses/by/4.0/

(c) (i) Open Access

\section{Abstract}

Background: Formaldehyde is commonly used for cadaver preservation in most anatomy laboratories with medical students at risk of acute toxic reactions involving the mucosal surface of the upper respiratory tract. Aım: To assess the nasal induced physical reactions from formaldehyde exposure among pre-clinical medical students. Materials and Method: This is a cross sectional, anonymous questionnaire-based study that included 119 preclinical medical students who took human anatomy laboratory course in the year 2012 at the College of Health Science of the Usman Danfodiyo University, Sokoto, Nigeria. Results: One hundred and nineteen students responded to the questionnaires. There were 82 males and 37 females with a ratio of $2.2: 1$. Fifty nine $(49.6 \%)$ of the respondents had watery rhinorrhea, nose itching 41 (34.5\%), excessive sneezing $34(28.6 \%)$, nasal obstruction $32(26.9 \%)$, hyposmia $23(19.3 \%)$ and 6 (5\%) epistaxis. Thirty $(29.2 \%)$ respondents had persistent nasal symptoms throughout the dissection session and nasal obstruction accounted for $40 \%$ of those affected. Majority of the respondents $113(95 \%)$ had no knowledge of health hazards and precautions against formaldehyde exposure. Conclusion: Watery rhinorrhea, followed by nasal obstruction were the most common nasal symptoms which were persistent in $36.7 \%$ and $40 \%$ of the respondents respectively throughout the anatomy dissection sessions. $\mathrm{Ni}$ nety five percent of the respondents had no knowledge of health hazards and precautions against formaldehyde exposure, therefore we recommend creation of awareness and precautionary measures against formaldehyde exposure in our Nigerian medical schools.

${ }^{*}$ Corresponding author.

How to cite this paper: Abdullahi, M., Zagga, A.D., Iseh, K.R., Amutta, S.B. and Aliyu, D. (2014) Nasal Response from Formaldehyde Exposure Used as Cadaver Preservative among Pre-Clinical Medical Students in a Nigerian Medical College. International Journal of Otolaryngology and Head \& Neck Surgery, 3, 173-178. http://dx.doi.org/10.4236/ijohns.2014.34032 


\section{Keywords}

\section{Formaldehyde, Nasal Symptoms, Health Hazards, Medical Students}

\section{Introduction}

Formaldehyde is characterized for its pungent odor, a colorless, flammable gas and soluble in water; its aqueous solution of about $37 \%$ formaldehyde is called formalin and is widely used in a tissue preservative in autopsy rooms and in anatomy laboratories to preserve cadaver [1]-[3], particularly in Nigerian medical schools [4].

Gross anatomy is one of the compulsory courses in medical and dental schools for the study of the normal human structural anatomy for which cadavers preserved with formalin are used for dissection [5]-[7]. Studies have shown that exposure to formaldehyde at a certain concentration causes irritation of the eyes and the respiratory tract [8] [9], because of the chemosensory effect on the nervus trigeminus resulting to reflex response such as sneezing, lacrimation, rhinorrhea [10]. The estimated threshold for odor perception, irritant effects involving the eyes, nose and throat are less than 0.5 parts per million (ppm), 0.5 - $1.0 \mathrm{ppm}$ and $1.0 \mathrm{ppm}$ respectively [11]. During dissection process, formaldehyde vapors are emitted from the cadaver, resulting to exposure especially the medical student(s) closer to cadaver, the exposure level are 2- to 3-fold higher than the mean indoor formaldehyde concentration [10] [12].

There are many ways of minimizing the hazards and exposure of formaldehyde in the anatomy laboratory: engineering controls for providing appropriate ventilation systems, alternative to formaldehyde as a tissue preservative, proper storage and waste disposal of formaldehyde [13]. For individual protection at risk of exposure especially the medical students, instructors and cadaver related workers should wear: protective devices activated carbon mask, goggle and rubber glove during working in gross anatomy laboratory [14].

However, the most cost effective initial step in minimizing hazard of formalin exposure involves the detailed discussion with the medical students before starting dissection with the aim of achieving a balance attitude toward the health hazard of formaldehyde in anatomy laboratory [1].

Most of these precautions stated above are achievable in the anatomical laboratories of the developed world especially the use of local exhaust ventilation (LEV) method source control for dissecting tables, which involves the modification of dissecting tables to include lateral exhaust slots along the perimeter of the area that supports the cadaver [15]. In contrast, this may not be the case for developing countries like Nigeria, where formaldehyde and its biological effect is still a common phenomenon [4] [16]. Studies in the western world and Nigeria: on the effect of formaldehyde exposure to students in gross anatomy laboratory showed that its effect on the eyes and the upper respiratory tract are common [1] [4] [8] [16]. The uptake of formaldehyde by the nasal mucosa has been demonstrated to be extremely high [17] and there is dearth of information on the detailed nasal response from formaldehyde exposure during dissection in the anatomy laboratory. The present study aimed to determine the nasal induced physical reactions from formaldehyde exposure among pre-clinical medical students during anatomy dissection.

\section{Materials and Methods}

The study employed a descriptive method using structured, self-administered questionnaires in obtaining vital information from the second and third year medical students, who took human anatomy laboratory course in the year 2012 at the College of Health Science of Usman Danfodiyo University, Sokoto, Nigeria. Institutional research ethical clearance was obtained from the ethical committee of Usman Danfodiyo University Teaching Hospital, Sokoto.

Out of 170 questionnaires, only 119 were completed and returned. The questionnaires comprised of: age, sex, types of physical reaction from the respiratory tract following formaldehyde exposure and knowledge of the respondents on the hazards and precautions of formaldehyde exposure. The inclusion criteria: respondents must be in contact with cadavers preserved with formalin. The exclusion criteria includes respondents with histories of asthma, dermatitis, and preexisting rhinitis with associated other nasal symptoms such as nasal obstruction, anosmia, epistaxis, itching of the nose and excessive sneezing. 
Data were analyzed using Statistical Package for the Social Sciences (SPSS) version 18 to determine the mean, standard deviation and frequency distributions and statistical significance between nasal obstruction and feeling of tightness of the chest during cadaver dissection in the anatomy laboratory using chi-square (2 tail test) with the level of significance set at $5 \%$.

\section{Results}

A total of one hundred and seventy questionnaires were distributed, 119 were completed and returned: response rate of $70 \%$. There were 82 males and 37 females with the ratio of 2.2:1. The age range was between 18 to 42 years with the mean age of $22 \pm 3.5$ years as shown in Table 1 .

Majority of the respondents had eyes irritation accounting for $88.2 \%$ and for nasal symptomatology: watery rhinorrhea accounted for 59 (49.9\%), followed by nose itching 41 (34.5\%), excessive sneezing 34 (28.6\%), nasal obstruction 32 (26.9\%), hyposmia 23 (19.3\%) and epistaxis 6 (5\%) as shown in Figure 1. Thirty (25.2\%) of the respondents had persistent nasal symptoms for which nasal obstruction accounted for $12(40 \%)$, watery nasal discharge 11 (36.7\%), excessive sneezing 5 (16.7\%) and itching of the nose $2(6.7 \%)$ as shown in Figure 2. Other respiratory tract symptoms from formaldehyde exposure includes: sore throat 31 (26.1\%), cough 27 (22.7\%), feelings of chest tightness 13 (10.9\%) and wheezing 10 (8.4\%) as shown in Figure 3. There was significant relationship between nasal obstruction and feeling of tightness of the chest $(\mathrm{p}<0.05)$ in the respondents exposed to formaldehyde. Majority 113 (95\%) of the respondents have no knowledge of health hazards and precautions against formaldehyde exposure.

Table 1. Age group, gender and grade level distributions of the respondents.

\begin{tabular}{|cc|}
\hline Age range & Number (\%) \\
\hline $18-20$ & $44(37)$ \\
$21-30$ & $72(60.5)$ \\
$31-40$ & $2(1.7)$ \\
$41-50$ & $1(0.8)$ \\
\hline Gender & \\
\hline Male & $82(68.9)$ \\
Female & $37(31.1)$ \\
\hline Grade level & \\
\hline Second year & $51(42.9)$ \\
$\quad$ Third year & $68(57.1)$ \\
\hline Major & \\
\hline The respondents were all preclinical medical students \\
\hline
\end{tabular}

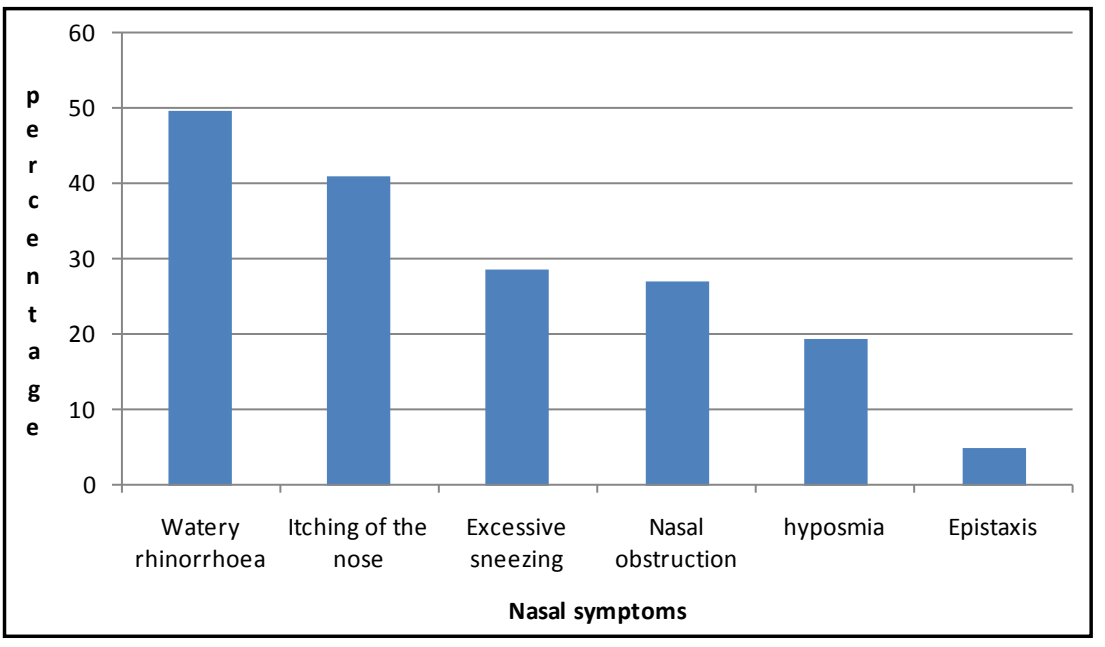

Figure 1. Nasal symptoms from formaldehyde exposure. 


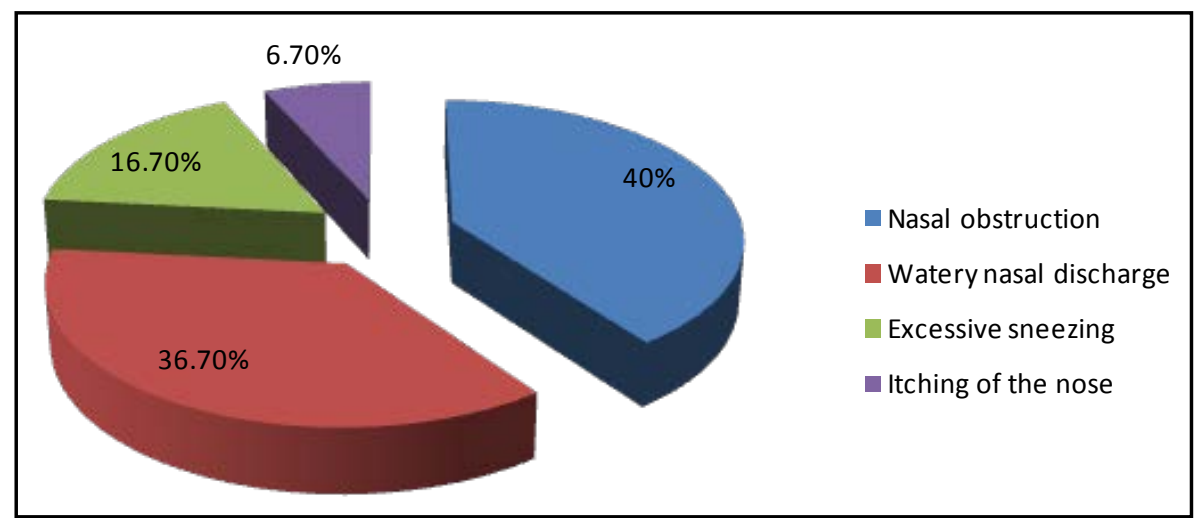

Figure 2. Persistent nasal symptoms from formaldehyde exposure.

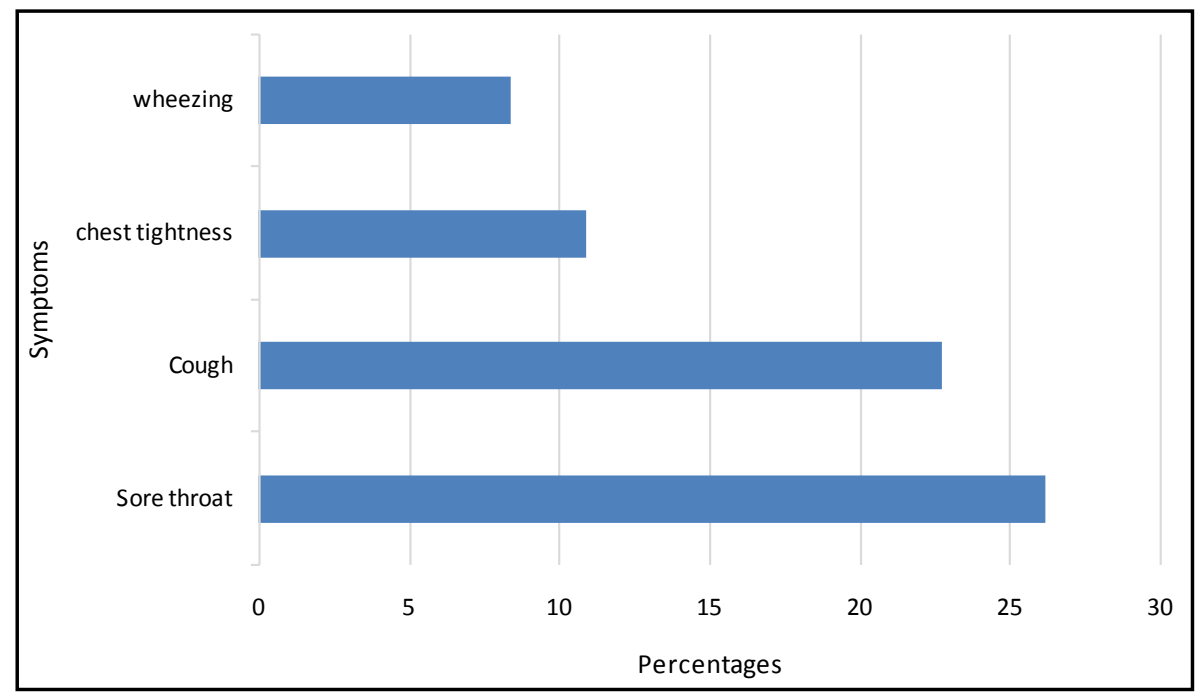

Figure 3. Other respiratory tract symptoms from formaldehyde exposure.

\section{Discussion}

Formaldehyde in aqueous solution (formalin) is widely used as a cadaver preservative, characterized by its pungent odor and the irritating effect to the eyes and the upper respiratory tract are well known unpleasant properties of formaldehyde in the dissecting anatomy laboratories [1] [18]. With emphasis on the irritative effect to the nasal mucosa from formaldehyde exposure, the present study showed that one of the most common reported nasal symptoms was watery rhinorrhea. This observation was in agreement with a report from Nigeria, on the excruciating effect of formaldehyde among 93 students in gross anatomy dissecting laboratory [19]: besides the unpleasant smell perceived by the respondents, running nose was the second most common symptom. The present study also showed that epistaxis was the least symptom from formaldehyde exposure which was similar to the work done by Wantke et al., in which only two of 45 students had epistaxis [20]. The precise mechanism for irritative formaldehyde exposure for non-allergic individual, is not known. However, in vitro studies suggested that formaldehyde may play a role as an irritant of the nasal mucosa by increasing the expressions of adhesion molecules on human mucosal microvascular endothelial cells [21].

The uptake of formaldehyde by the nasal mucosa has been demonstrated to be extremely high and in the presence of nasal blockage with associated mouth breathing, more formaldehyde can probably reach the lungs with resultant formaldehyde induced bronchoconstriction [17] [22] [23]. This could explain the statistical significance of our respondents with nasal obstruction and feelings of chest tightness. However, our present study is limited by the inability to measure the formaldehyde air concentration in our anatomy laboratory following exposure which may be responsible for the lower respiratory tract symptoms experienced by our respondents. 
Persistent symptoms during cadaver dissection as seen in $25.2 \%$ of our respondents, may impair the medical student's concentration and reduced the zeal to learn gross anatomy throughout the dissection period. However, these persistent symptoms are relieved immediately after leaving the dissection room.

Hazards of uncontrolled formaldehyde exposure is well documented in literature [1] [2] [13]. Emphasis on the need for detailed discussion with the students before starting dissection course is important, with the aim of achieving a more critical, balanced attitude toward the health hazard of formaldehyde and other forms of formaldehyde protection programs [1] [13]. The present study showed that $95 \%$ of the respondents have no knowledge of health hazards and precaution against formaldehyde exposure and this may be a contributory factor for undue exposure bearing in mind that formaldehyde had been classified as human carcinogen that cause nasopharyngeal carcinoma [24].

Many precautionary measures against formaldehyde exposure are well documented in literature: engineering controls by providing appropriate ventilation systems, alternative to formaldehyde as a tissue preservative such as the use of propylene glycol ether and phenol in combination etc., proper storage and waste disposal of formaldehyde, the use of protective devices activated carbon mask, goggle and rubber glove during working in gross anatomy laboratory [1] [13]. With serious commitments from the institution(s) involved and the government, this is achievable in order to minimize the hazards of formaldehyde.

\section{Conclusion}

Watery rhinorrhea and nasal obstruction were the most common nasal symptoms and were persistent in 36.7\% and $40 \%$ of the respondents respectively throughout the anatomy dissection session. There is statistical significance $(<0.05 \%)$ of respondents with nasal obstruction and feeling of chest tightness. Ninety five percent of the respondents had no knowledge of health hazards and precautions against formaldehyde exposure. We recommend creation of awareness and precautionary measures against formaldehyde exposure in our Nigerian medical schools.

\section{References}

[1] Pabst, R. (1987) Exposure to Formaldehyde in Anatomy: An Occupational Health Hazard? The Anatomical Record, 219, 109-112. http://dx.doi.org/10.1002/ar.1092190202

[2] Vimercati, L., Carus, A., Martino, T., Galise, I., Minunni, V., Caputo, F., et al. (2010) Formaldehyde Exposure and Irritative Effects on Medical Examiners, Pathologic Anatomy Post-Graduate Students and Technicians. Iranian Journal of Public Health, 39, 26-34.

[3] Hisamitsu, M., Okamoto, Y., Yonekura, S., Sakurai, D., Horiguchi, S., Hanazawa, T., et al. (2011) The Influence of Environmental Exposure to Formaldehyde in Nasal Mucosa of Medical Students during Cadaver Dissection. Allergology International, 60, 373-379. http://dx.doi.org/10.2332/allergolint.10-OA-0210

[4] Ajao, S.M., Adepoju, O.O., Olayaki, L.A., Olawepo, A., Adefolaju, A.G. and Jimoh, S.A. (2011) Physical Reactions of Nigerian Health Science Students to Formaldehyde Used as Cadaver Preservatives. Research Journal of Applied Sciences, 6, 20-24. http://dx.doi.org/10.3923/rjasci.2011.20.24

[5] Ohmichi, K., Komiyama, M., Matsuno, Y., Fukata, H., Ohmichi, M., Kadota, T., et al. (2006) Relationship between Exposure to Formaldehyde and Immunoglobulin E (IgE) Production during the Gross Anatomy Laboratory. Journal of Health Science, 52, 642-647. http://dx.doi.org/10.1248/jhs.52.642

[6] Horst, W.K., Helmut, W., Robert, L., Snipes, J.P., Friedrich, P., Gabriele, R.E. and Baumgart, V. (2008) The Dissection Course-Necessary and Indispensable for Teaching Anatomy to Medical Students. Annals of Anatomy, 190, 116122.

[7] Biasutto, S.N., Lucas, I., Caussa, L.I. and Criado, L.E. (2006) Teaching Anatomy: Cadaver vs Computers. Annals of Anatomy-Anatomischer Anzeiger, 188, 187-190. http://dx.doi.org/10.1016/j.aanat.2005.07.007

[8] Tanaka, K., Nishiyama, K., Yaquinuma, H., Sasaki, A., Maeda, T., Kaneko, S.Y., et al. (2003) Formaldehyde Exposure Level and Control Measure during Anatomy Dissection Course. Kaibogaku Zasshi, 78, 43-51.

[9] Kulle, T.J. (1993) Acute Odour and Irritant Response in Healthy Nonsmokers with Formaldehyde Exposure. Inhalational Toxicology, 5, 323-332. http://dx.doi.org/10.3109/08958379308998389

[10] Ohmichi, K., Komiyama, M., Matsuno, Y., Takanashi, Y., Miyamto, H., Kadota, T., et al. (2006) Formaldehyde Exposure in a Gross Anatomy Laboratory-Personal Exposure Level Is Higher than Indoor Concentration. Environmental Science and Pollution Research, 13, 120-124. http://dx.doi.org/10.1065/espr2005.06.265

[11] Pausteembach, D., Alarie, Y., Kulle, T., et al. (1997) A Recommended Occupational Exposure Limit for Fomaldehyde: 
Evaluation of Sensory Irritation in Relation to Carcinogenicity. Journal of Toxicology and Environmental Health, 50, 217-264. http://dx.doi.org/10.1080/009841097160465

[12] Chia, S.E., Ong, C.N., Foo, S.C., et al. (1992) Medical Students’ Exposure to Formaldehyde in a Gross Anatomy Dissection Laboratory. The Journal of American College Health, 41, 115-119. http://dx.doi.org/10.1080/07448481.1992.9936310

[13] Jayalakshmi, K., Ravikumar, H., Naidu, J. and Raghavendra, R. (2011) A Silent Killer in the Laboratory-Formaldehyde: Review of Effects and Management. International Journal of Oral \& Maxillofacial Pathology, 2, 13-19.

[14] Kajorn, L. and Pensri, W. (2010) Formaldehyde Exposure of Medical Student and Instructors and Clinical Symptoms during Gross Anatomy Laboratory in Thammasat University. Journal of the Medical Association of Thailand, 93, 92-98.

[15] Keil, B.C., Akbar-Khanzadeh, F. and Konecny, A.K. (2001) Characterizing Formaldehyde Emission Rates in a Gross Anatomy Laboratory. Applied Occupational and Environmental Hygiene, 16, 967-972. http://dx.doi.org/10.1080/104732201300367227

[16] Ajao, M.S., Alimi, T.A., Yahaya, W.B., Eweoya, O.O., Jimoh, O.R. and Olawepo, A. (2008) Gender Effect on Physical Reaction of Health Science at First Encounter with Cadaver Using Pearson Chi-Square Test. Research Journal of Medical Science, 2, 100-103.

[17] Egle, J.L. (1972) Retention of Inhaled Formaldehyde, Propionaldehyde, and Acrolein in the Dog. Archives of Environmental Health, 25, 119-124. http://dx.doi.org/10.1080/00039896.1972.10666147

[18] Lang, I., Bruckner, T. and Triebig, G. (2008) Formaldehyde and Chemosensory Irritation in Humans: A Controlled Human Exposure Study. Regulatory Toxicology and Pharmacology, 50, 23-26. http://dx.doi.org/10.1016/j.yrtph.2007.08.012

[19] Onyije, F.M. and Avwioro, O.G. (2012) Excruciating Effect of Formaldehyde to Students in Gross Anatomy Dissection Laboratory. International Journal of Occupational and Environmental Medicine, 3, 92-95.

[20] Wantke, F., Focke, M., Hemmer, W., Tschabitschel, M., Gann, M., Tappler, P., et al. (1996) Formaldehyde and Phenol Exposure during an Anatomy Dissection Course: A Possible Source of lgE-Mediated Sensitization. Allergy, 51, 837841.

[21] Kim, W.J., Terada, N., Nomura, T., Takahashi, R., Lee, S.D., Park, J.H., et al. (2002) Effect of Formaldehyde on the Expression of Adhesion Molecules in Nasal Pathogenesis of Sick Building Syndrome. Clinical \& Experimental Allergy, 32, 287-295. http://dx.doi.org/10.1046/j.1365-2222.2002.01301.x

[22] Holmstrőm, M. and Wilhelmsson, B. (1988) Respiratory Symptoms and Pathophysiological Effect of Occupational Exposure to Formaldehyde and Wood Dust. Scandinavian Journal of Work, Environmental \& Health, 14, 306-311. http://dx.doi.org/10.5271/sjweh.1915

[23] Alexandersson, R., Kolmodin-Hedman, B. and Hedenstierna, G. (1982) Exposure to Formaldehyde: Effect on Pulmonary Function. Archives of Environmental Health, 37, 279-284. http://dx.doi.org/10.1080/00039896.1982.10667579

[24] Cogliano, V.J., Grosse, Y., Baan, R.A., Straif, M.B., et al. (2005) Working Group for Volume 88. Meeting Report: Summary of IARC Monograph on Formaldehyde, 2-Butoxyethanol and 1-Tert-Butoxy-2-Propanol. Environmental Health Perspectives, 13, 1205-1208. http://dx.doi.org/10.1289/ehp.7542 
Scientific Research Publishing (SCIRP) is one of the largest Open Access journal publishers. It is currently publishing more than 200 open access, online, peer-reviewed journals covering a wide range of academic disciplines. SCIRP serves the worldwide academic communities and contributes to the progress and application of science with its publication.

Other selected journals from SCIRP are listed as below. Submit your manuscript to us via either submit@scirp.org or Online Submission Portal.
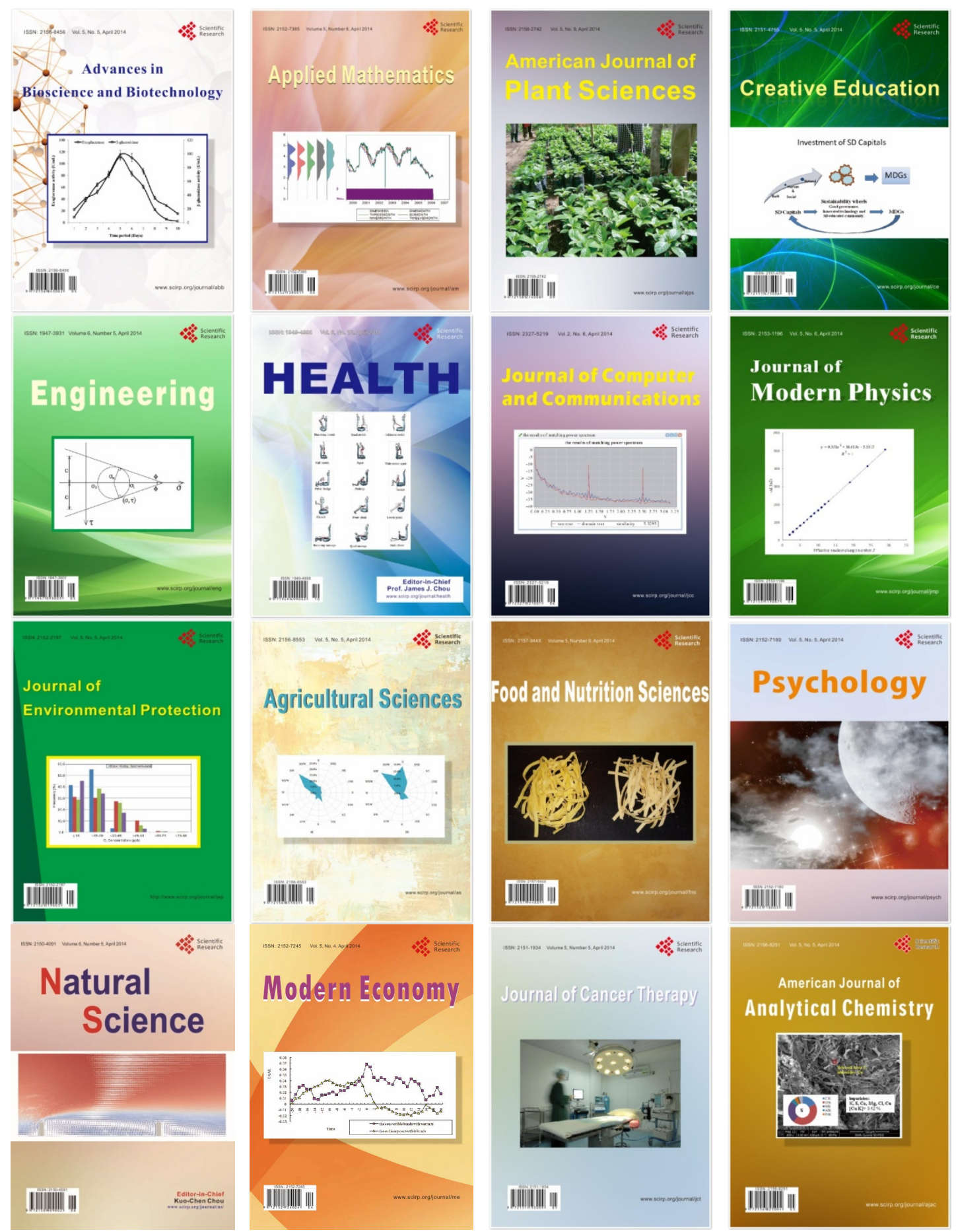